\title{
Orosomucoid in urine predicts cardiovascular and over-all mortality in patients with Type II diabetes
}

\author{
M.S. Christiansen ${ }^{1}$, E.Hommel ${ }^{2}$, E.Magid ${ }^{1}$, B. Feldt-Rasmussen ${ }^{3}$ \\ ${ }^{1}$ Department of Clinical Biochemistry, Amager Hospital, Copenhagen S, Denmark \\ ${ }^{2}$ Department of Internal Medicine, Bispebjerg Hospital, Copenhagen, Denmark \\ ${ }^{3}$ Department of Nephrology and Endocrinology, Rigshospitalet, Copenhagen, Denmark
}

Diabetologia (2002) 45: 115-120

On page 118, third paragraph, line one: the first ' 14 ' should be deleted and the sentence should read: "Of patients with normal UAER $(n=251) 14$ died compared with 27 patients with increased UAER $(n=179 ; p<0.001)$."

\section{Butyrylcholinesterase $\mathrm{K}$ variant on chromosome 3q is associated with Type II diabetes in white Caucasian subjects}

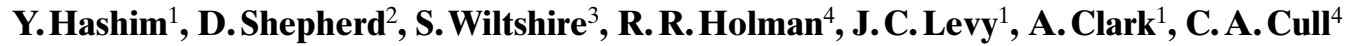 \\ ${ }^{1}$ Diabetes Research Laboratories, Oxford Centre for Diabetes, Endocrinology and Metabolism, University of Oxford, \\ Oxford, UK \\ ${ }^{2}$ Institute of Molecular Medicine, John Radcliffe Hospital, Oxford, UK \\ ${ }^{3}$ Wellcome Trust Centre for Human Genetics, University of Oxford, UK \\ ${ }^{4}$ Diabetes Trials Unit, Oxford Centre for Diabetes, Endocrinology and Metabolism, Radcliffe Infirmary, Oxford, UK
}

Diabetologia (2001) 44: 2227-2230

In Table 1 , the $p$ value quoted as 0.00079 should read 0.0079 and that quoted as 0.00017 should read 0.0017. Furthermore, on page 2228, right column, line 14 and on page 2230 , left column, line 11 , 'means \pm SEM' should read 'means SD'. 